\title{
Exploring Metabolic Responses of Potato Tissue Induced by Electric Pulses
}

\author{
Federico Gómez Galindo • Lars Wadsö • \\ António Vicente • Petr Dejmek
}

Received: 28 December 2007 / Accepted: 4 April 2008 /Published online: 3 June 2008

(C) Springer Science + Business Media, LLC 2008

\begin{abstract}
In this study, we investigated the metabolic responses of potato tissue induced by pulsed electric field (PEF). Potato tissue was subjected to field strengths ranging from 30 to $500 \mathrm{~V} / \mathrm{cm}$, with a single rectangular pulse of $10 \mu \mathrm{s}$, $100 \mu \mathrm{s}$, or $1 \mathrm{~ms}$. Metabolic responses were monitored using isothermal calorimetry, changes on electrical resistance during the delivery of the pulse, as well as impedance measurements. Our results show that the metabolic response involves oxygen consuming pathways as well as other unidentified events that are shown to be insensitive to metabolic inhibitors such as $\mathrm{KCN}$ and sodium azide. The metabolic response is strongly dependent on pulsing conditions and is independent of the total permeabilization achieved by the pulse. Evidence shows that calorimetry is a simple and powerful method for exploring conditions for metabolic stimulation, providing information on metabolic responses that can not be obtained from electrical measurements. This study set the basis for further investigations on defense-related consequences of PEF-induced stress.
\end{abstract}

\footnotetext{
F. Gómez Galindo $(\bowtie) \cdot A$. Vicente

IBB-Institute for Biotechnology and Bioengineering,

Centro de Engenharia Biológica, Universidade do Minho,

Campus de Gualtar,

4710-057 Braga, Portugal

e-mail: Federico.Gomez@deb.uminho.pt

e-mail: federico.gomez@food.lth.se

L. Wadsö

Division of Building Materials, Lund University,

P.O. Box 118, SE-221 00 Lund, Sweden

P. Dejmek

Department of Food Technology, Engineering and Nutrition, Lund University,

PO Box 124, SE-221 00 Lund, Sweden
}

Keywords Metabolic stimulation · Isothermal calorimetry · Impedance $\cdot$ Electrical resistance

\section{Introduction}

The application of pulsed electric fields (PEF) may cause lethal damage to cells or induce sublethal stress by transient permeabilization of cell membranes and electrophoretic movement of charged species between cellular compartments. ${ }^{1}$ The technique is, in its lethal version, at very high field strength, used for the inactivation of microorganisms in foods $\mathrm{s}^{2,3}$ and can, at lower field strength, be used for the improvement of extraction yield ${ }^{4,5}$ or increased rate of drying. ${ }^{6,7}$ In its nonlethal version, physiological responses to PEF-induced stress are still largely unknown. It has been reported that PEF affects metabolism, including an oxidative burst with the consequent generation of reactive oxygen species (ROS), ${ }^{8,9}$ and the stimulation of the production of secondary metabolites such as increased yields of a cytostatic compound in cell culture of Taxus chinensis ${ }^{10}$ and of antioxidants and phytoesterols from oil seeds and fruits. ${ }^{11,12}$

To our knowledge, little attention has been given to the application of PEF-induced stress to postharvest processing. Traditionally, postharvest processing is mainly concerned with slowing down or inactivating metabolic processes in the harvested product. Apart from the effects of ripening and senescence, reports on the active plant metabolism including stress-induced physiological events are not common in the literature. Recently, Gómez Galindo et al. ${ }^{13}$ reviewed the importance and prospects of plant stress in postharvest treatments. Observed metabolic stress consequences include potato sweetening in cold storage, chilling damage of tomato, and potato tissue suberization following industrial peeling. As most stresses include an 
oxidative burst and concomitant antioxidant defenses, the general utilization of stresses has been proposed as a means of increasing the plant tissue antioxidant levels in both preharvest ${ }^{14}$ and postharvest. ${ }^{15}$

Inducing stress by chemical means is not an attractive proposition for a healthy food product. Physical intervention, apart from ionizing radiation, is likely to be a more acceptable candidate. However, unlike chemical stress, temperature or pressure stress cannot be easily targeted. The induction of sublethal stress by the application of PEF is likely to be a potential industrial alternative for metabolic stimulation, being unique as a stress regarding its primary effect on cell membranes and by causing a homogeneous effect over the whole treated tissue. Therefore, research is needed at first to find appropriate conditions (e.g., pulse shape and polarity, number, width, and interpulse time) for PEF-induced metabolic stimulation. These conditions can then be refined upon an understanding of physiological responses.

In this paper, we explore gross metabolic responses of potato tissue induced by the application of PEF at different pulse widths and strengths. Electrical properties of the tissue and metabolic heat rates were measured. Changes in metabolic heat rate were studied using isothermal calorimetry. Calorimetric measures of the rate of heat production are proportional to metabolic rates and provide a direct indication of integrated metabolic responses such as respiration and reaction to stress. ${ }^{16}$

\section{Materials and Methods}

\section{Raw Material, Handling, and Storage}

Potato tubers (Solanum tuberosum L. cv. Bintje) grown in the south of Sweden were used. The potatoes were harvested and placed in a storage room, forming piles of $4.5 \mathrm{~m}$ maximum height. The potatoes were stored at $4^{\circ} \mathrm{C}$ and approximately $100 \% \mathrm{RH}$ in the dark without the addition of sprouting inhibitors. These are conditions routinely practiced by the producer. Potato tubers free from defects, stored under the described conditions for 3 months, were selected at the farm storage facility and transported to our laboratory in plastic bags kept in insulated boxes on ice. The potatoes were then placed in a closed refrigerated chamber at $4^{\circ} \mathrm{C}$ and saturated atmosphere in darkness until used.

\section{Sample Preparation}

Medium-sized potato tubers $(13.0 \pm 3.0 \mathrm{~cm}$ in length, $7.0 \pm$ $0.5 \mathrm{~cm}$ diameter) were manually washed and peeled. One slice, $15 \mathrm{~mm}$ thick, was obtained from the center of a single tuber. The slice was oriented perpendicular to the major tuber axis. A rectangular cross-section sample, $15 \mathrm{~mm}$ long and $6.0 \mathrm{~mm}$ wide, was obtained from the phloem parenchyma tissue of the slice using a pair of parallel sharp blades. Immediately after cutting, the sample was rinsed with distilled water and gently blotted with medical wipes to remove the excess of water from the sample surface. The rectangular samples, three to four per tuber, were subjected to different treatments described in detail below.

\section{Pretreatments}

The rectangular samples were either PEF treated or pretreated with one of the following metabolic inhibitors before the PEF treatment: (1) $10 \mathrm{mM} \mathrm{KCN}$ in $10 \mathrm{mM}$ MES for $30 \mathrm{~min}$, (2) $10 \mathrm{mM}$ salicylhydroxamic acid (SHAM) with $10 \mathrm{mM} \mathrm{KCN}$ in $10 \mathrm{mM}$ MES for $30 \mathrm{~min}$, and (3) $10 \mathrm{mM}$ solution of sodium azide in $5 \mathrm{mM} \mathrm{KCl}$ for $15 \mathrm{~min}$. The ratio of grams of potato tissue to milliliters of solution was 1:100. All pretreatments were performed at room temperature without stirring of the solution. Control samples were neither chemically nor PEF treated.

\section{Experimental Setup and Electrical Treatment}

The experimental setup for PEF treatment of the samples and measurement of the electrical response and rate of heat production consisted of a $20 \mathrm{ml}$ polyethylene ampoule with a plastic screw cap where a $10-\mathrm{mm}$ opening was made. In this opening, a Teflon insert with two steel electrodes was fastened with a nut. Vapor tightness was assured by an o-ring. The ends of each steel electrode were soldered to a 1-mm cable. In the inner side of the cap, the cables were connected to the sample holder which consisted of two parallel, flat stainless steel electrodes $(35 \mathrm{~mm}$ long and $10 \mathrm{~mm}$ wide) separated by $6 \mathrm{~mm}$. The sample holder was tightly closed inside the ampoules. In the outer side of the cap, the cables connected the ampoules containing the sample holder in series to a reference resistor $(300 \Omega)$ and the pulse generator.

Electric pulses were delivered axially to the tissue using a Cellect electromanipulation instrument (BioFusion SCI $\mathrm{AB}$, Sweden). Samples were treated at varying voltages $(18,60,120,180,240$, and $300 \mathrm{~V}$, which corresponds to the nominal electric field strength of $30,100,200,300,400$, and $500 \mathrm{~V} / \mathrm{cm}$ ) with a single rectangular pulse of $10 \mu \mathrm{s}$, $100 \mu \mathrm{s}$, or $1 \mathrm{~ms}$.

Measurements

\section{Electrical Response of the Tissue}

The resistance of the tissue samples during the pulsing period was measured as the potential difference over the 
reference resistor and was stored and observed on a digital storage oscilloscope (EM621 digital oscilloscope, ETC instruments, Slovak Republic) connected to the system. At the last part of the pulse period, the current-time relationship was converted into the "instantaneous" resistance by dividing the applied voltage by the time-dependent current, $V / I(t)$. The resistance of the tissue was then evaluated by subtracting the reference resistance. ${ }^{17,18}$ Four measurements were done for each PEF condition.

\section{Measurements of the Rate of Heat Production}

The rate of heat production after the application of PEF was continuously measured in a TAM Air isothermal calorimeter (Thermometric AB, Järfälla, Sweden), as described by Rocculi et al. ${ }^{19}$ This calorimeter has a sensitivity (precision) of $\pm 10 \mu \mathrm{W} .^{20}$ This instrument contains eight twin calorimeters. In each calorimeter, heat is allowed to flow between the reaction vessel containing the sample and a heat sink, the temperature of which is kept essentially constant. The heat transfer takes place through a heat flow sensor that is located between the vessel and the heat sink.

Weighted samples were placed in the $20 \mathrm{ml}$ plastic ampoules described in the experimental setup section and placed in the calorimeter at $20^{\circ} \mathrm{C}$. Each calorimeter had its own reference that consisted of a sealed $20 \mathrm{ml}$ glass ampoule containing $4 \mathrm{ml}$ of water. The eight calorimeters permitted eight simultaneous measurements of the rate of heat production. In this way, the control, a nonpretreated and two pretreated samples were distributed in four ampoules. The other four ampoules were used to duplicate the measurements. The experiment was done twice, allowing four measurements for each PEF condition.

The isothermal measurements were performed for a period of about $3 \mathrm{~h}$. Baselines (BL) were recorded before or after each measurement. The primary output from the heat flow sensors in the calorimeters (a voltage) was recorded by computer from the digitized output of the calorimeters. The corresponding thermal powers (heat production rates) were calculated by the following equation:

$P=\varepsilon^{*} \frac{V_{\mathrm{S}}-V_{\mathrm{BL}}}{M}$

where $P\left(\mathrm{~mW}^{-1}\right)$ is the specific thermal power of the potato sample, $\varepsilon$ the calibration coefficient of the calorimeter $\left(\mathrm{mW} \mathrm{mV}^{-1}\right), V_{\mathrm{S}}$ the voltage signal from the calorimeter $(\mathrm{mV}), V_{\mathrm{BL}}$ the corresponding voltage $(\mathrm{mV})$ recorded for the baseline, and $M$ is the mass ( $\mathrm{g}$ ) of the sample. The calibration coefficients were calculated from electrical calibrations made at $20^{\circ} \mathrm{C}$.
To correct the thermal power values for the thermal inertia of the apparatus (i.e. the delay between heat being released by the sample and the heat flow causing the measured voltage), the Tian equation was used ${ }^{21}$ :

$P_{\mathrm{c}}=P+\tau \mathrm{d} P / \mathrm{d} t$

where $P_{\mathrm{c}}\left(\mathrm{mW} \mathrm{g}^{-1}\right)$ is the corrected specific thermal power of the sample and $\tau$ is the time constant. The time constant is equal to the quotient between the heat capacity of the system (usually the vessel holder and the reaction vessel and its contents) and the heat conductance of the heat flow sensor. $^{21}$

A MATLAB programme was written to apply Eqs. 1 and 2 to the voltage signal from the potato samples after the different treatments (MATLAB version 6.5, MathWork, Inc., MA, USA). The MATLAB programme included noise reduction to reduce the noise produced by the derivative in the Tian correction.

\section{Joule Heating}

The contribution of Joule heating to the calorimetric measurements was estimated as:

$Q=\left(\frac{V}{R_{\mathrm{ext}}+R_{\mathrm{s}}}\right)^{2} R_{\mathrm{s}} \times \Delta t$

where $Q(\mathrm{~J})$ is the heat generated by the electric current, $V$ is the applied voltage, $R_{\text {ext }}$ is the reference resistance connected in the system $(300 \Omega), R_{\mathrm{S}}$ is the resistance of the sample at a certain field strength, and $\Delta t(\mathrm{~s})$ is the electric field width.

\section{Pre- and Postpulse Electrical Measurement}

Sample impedance was measured prior to pulsing and $30 \mathrm{~s}$ to 3 min after pulsing by using a low-voltage sinusoidal wave form at $5 \mathrm{~V}$ and $1 \mathrm{kHz}$, as described by Chalermchat. ${ }^{18}$ The wave form was generated by a function generator (PC function generator, K8016, Velleman instruments, Belgium). A constant resistor of $300 \Omega$ was connected in series in the circuit between the samples and the function generator in order to monitor the responding voltage of the whole system. The responding voltage was monitored and recorded by the digital oscilloscope. The resistance of the samples, $R_{\mathrm{s}}$, was then calculated as:

$R_{\mathrm{s}}=300\left(5 / V_{\mathrm{f}}-1\right)$

where $V_{\mathrm{f}}$ is the response voltage. Four measurements were done for each PEF condition. 


\section{Results}

Electrical Response of the Tissue During the Delivery of the Pulse

The final electrical resistance of the potato sample during the delivery of the pulse plotted against the applied nominal electric field strength at three different field widths is shown in Figure 1. As the applied voltage and the reference resistance are constant and the sample resistance changes during the pulse, the actual field strength experienced by the tissue varies. The initial field strength was within $10 \%$ of the nominal field strength for the samples. In a separate experiment, we found that the contact resistance was negligible. At 100 and $10 \mu \mathrm{s}$, no measurements could be done in the oscilloscope at nominal electric fields $<100$ and $<200 \mathrm{~V} / \mathrm{cm}$, respectively. At the longer field widths of $1 \mathrm{~ms}$ and $100 \mu \mathrm{s}$, the resistance decreased markedly at the nominal fields of about $<100$ to $200 \mathrm{~V} / \mathrm{cm}$, followed by a slight decrease after $200 \mathrm{~V} / \mathrm{cm}$. At field strengths of 400 and $500 \mathrm{~V} / \mathrm{cm}$, the resistance values at these field widths are practically the same. At the field width of $10 \mu \mathrm{s}$, the portion of the curve showing a slower decrease of the resistance was evident only above $400 \mathrm{~V} / \mathrm{cm}$. At a field strength of $500 \mathrm{~V} / \mathrm{cm}$, the resistance value at this field width is only slightly higher than those at higher field widths.

\section{Effect of PEF on Metabolic Activity}

\section{Calorimetric Measurements}

An example of the results from the calorimetric measurements of a PEF-treated potato tissue $(400 \mathrm{~V} / \mathrm{cm} ; 1 \mathrm{~ms})$ is

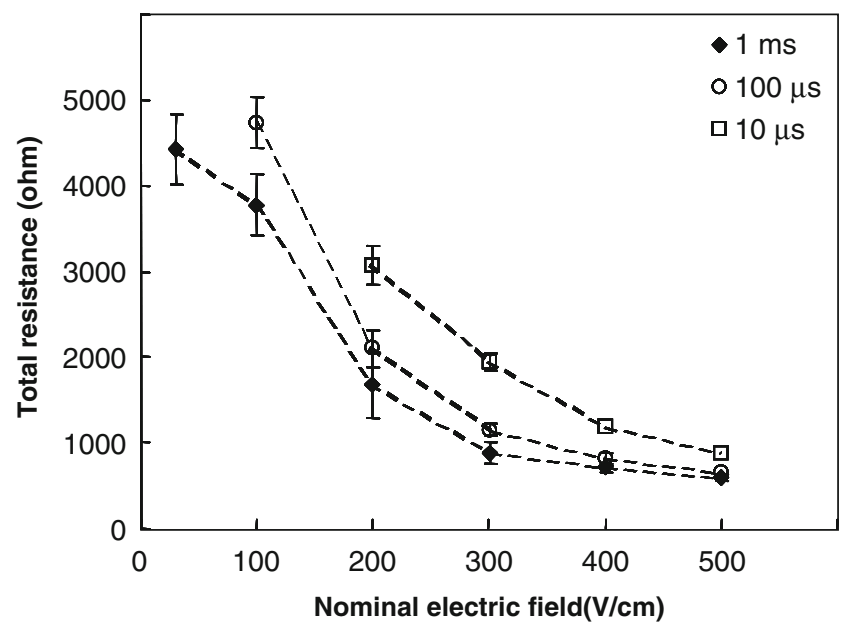

Fig. 1 Total resistance of potato samples during the application of unipolar, rectangular pulses at different field strengths and widths. Each given value is the average of four replicates. Error bars are the standard deviation of the mean

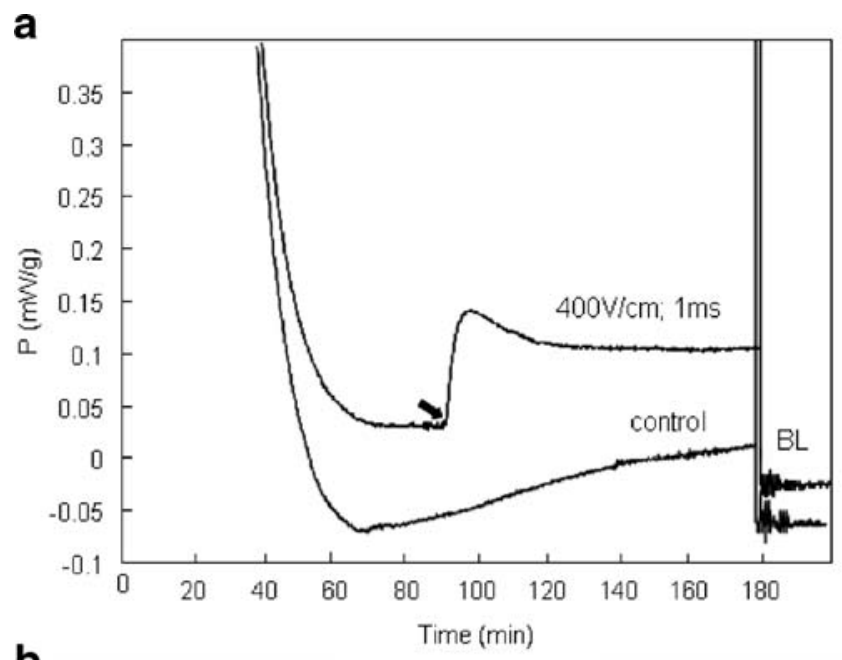

b

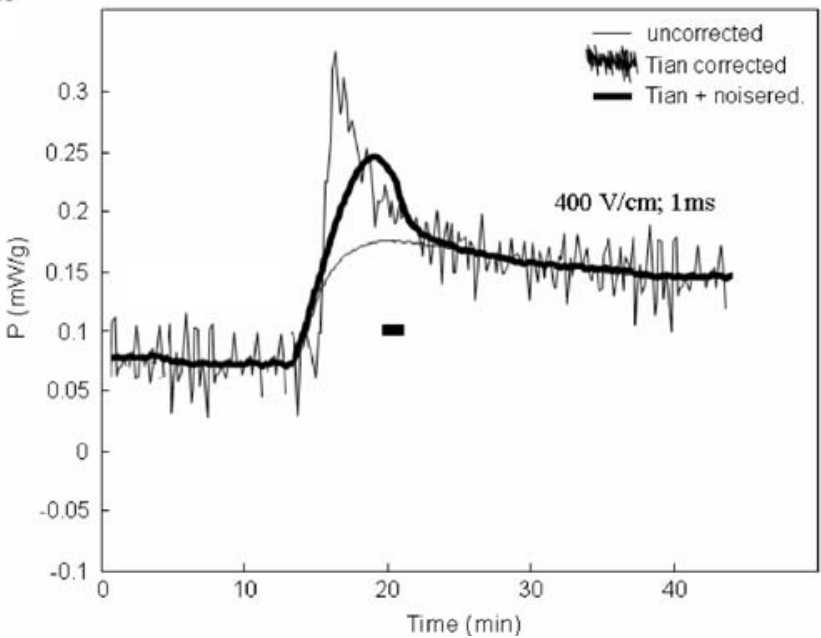

Fig. 2 Calorimetric measurements of metabolic heat rates. a Typical calorimeter output from potato tissue subjected to an electric pulse. After an initial disturbance, PEF was applied (indicated with an arrow in the upper curve). PEF conditions are indicated next to the curve. The experiment was interrupted after $3 \mathrm{~h}$ and the baseline $(B L)$ was recorded. b The thermal power was corrected with Eq. 2 and noise reduction was applied to the result. The contribution of Joule heating to the total heat generated by the sample after the application of PEF is represented by the small black rectangular area below the peak of the curve

shown in Figure 2a. Each time an ampoule was charged into a calorimeter, there was an initial disturbance lasting for at least $70 \mathrm{~min}$. After that, the true thermal power from the samples was measured. In the untreated sample (control), the thermal power increased during the time of the measurements; this increase can be attributed to woundinduced metabolism. ${ }^{22}$ For the sample to be PEF-treated, PEF was applied either when the thermal power was stable (indicated with an arrow in Figure 2a) or immediately after the thermal power started to increase. Immediately after the application of the electric field, the thermal power increased dramatically showing a peak that reached a maximum after about $5 \mathrm{~min}$. The thermal power then decreased to a certain value after which little changes were detected. This value 
was always higher than that at the beginning of the peak. The experiment was interrupted after $3 \mathrm{~h}$ by taking the samples out of the calorimeter. This interruption caused a disturbance lasting for at least 50 min (omitted in Figure 2a) before the baseline could be recorded.

The thermal power was corrected using Eq. 2. An example of the result is shown in Figure $2 b$, where the thin line represents the evolution of thermal power with time and the thick line represents the Tian-corrected, noisereduced thermal power vs. time. In the figure, the thermal powers corresponding to the initial disturbance of the calorimeter have been subtracted. As an electrical current is flowing, Joule heating is taking place. The contribution of Joule heating to the total heat generated by the sample after the application of PEF is represented by a rectangular area below the peak of the curve.

\section{Influence of PEF Treatments on Thermal Power}

From the four replicates done for each treatment, average corrected curves were obtained (see Figure $3 \mathrm{a}$ for the results obtained using pulse width of $1 \mathrm{~ms}$. To facilitate their comparison, the thermal powers before the pulse have been subtracted and the peaks have been normalized to start at the origin). The maximum thermal power of the peak of the curves $\left(P_{\max }\right)$ was used to compare the different treatments. Figure $3 \mathrm{~b}$ shows the results of $P_{\max }$ obtained at different pulse widths and intensities. At $10 \mu \mathrm{s}$, only a field strength of $500 \mathrm{~V} / \mathrm{cm}$ resulted in a small peak. At $100 \mu \mathrm{s}$, peaks of similar size were obtained at field strengths higher than $100 \mathrm{~V} / \mathrm{cm}$. At $1 \mathrm{~ms}$, at field strengths higher than $200 \mathrm{~V} / \mathrm{cm}$, there is a dramatic increase in the maximum values of thermal power compared with those obtained at $100 \mu \mathrm{s}$.

\section{Influence of Metabolic Inhibitors on Thermal Power}

An example of the effect of pretreating the potato samples with $\mathrm{KCN}$ (an inhibitor of the cytochrome pathway of electron transport and peroxidase activity for $\mathrm{H}_{2} \mathrm{O}_{2}$ production), alone or in combination with SHAM (an inhibitor of the alternative pathway of electron transport in mitochondria), before the application of PEF ( $400 \mathrm{~V} / \mathrm{cm} ; 1 \mathrm{~ms})$ on thermal power is shown in Figure 4. The curves are average curves from four replicates. Pretreatments with the tested metabolic inhibitors substantially decreased the response of the tissue to the PEF treatment. There was little difference between the results obtained with $\mathrm{KCN}$ alone and those obtained when used in combination with SHAM. From the figure, the portion of $P_{\max }$ that was KCN-sensitive could be calculated. In Table 1, the $\mathrm{KCN}$-sensitive and the $\mathrm{KCN}$-insensitive percentages of $P_{\max }$ after PEF application at different conditions are reported. The results show that, at all conditions, a high
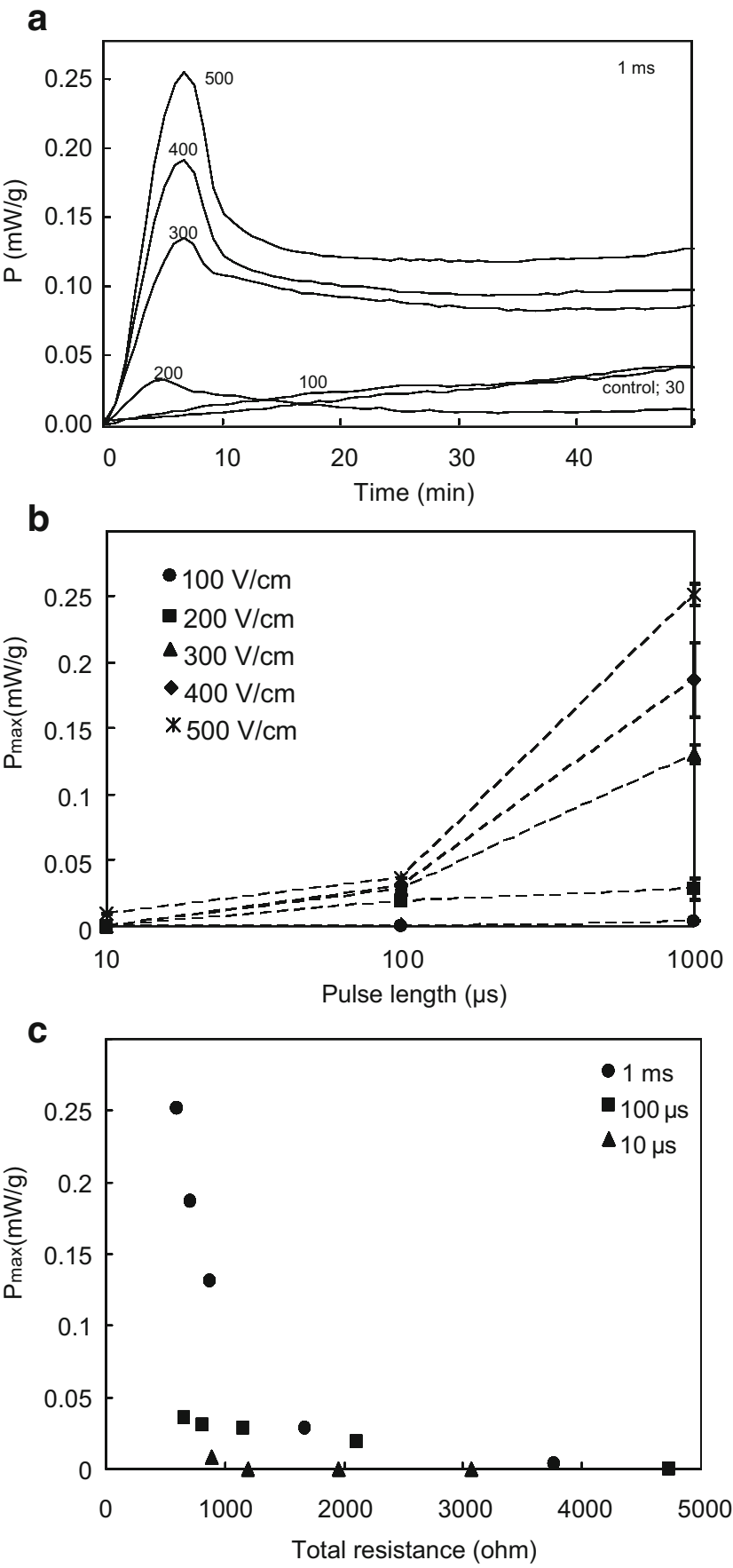

Fig. 3 Effect of pulsing conditions on thermal power. a Effect of pulse strength on thermal power. The pulse length is $1 \mathrm{~ms}$. Average curves from four replicates are reported. To facilitate comparison between the treatments, the thermal powers before the pulse have been subtracted and the peaks have been normalized to start at the origin. The curves are the final result of Tian correction and noise reduction of thermal power results. b Effect of pulse strength and width on the maximum thermal power $\left(P_{\max }\right)$, measured as the maximum value of the peak of the thermal power curves showed in a. c $P_{\max }$ as a function of total resistance of the potato samples during the application of the pulse 


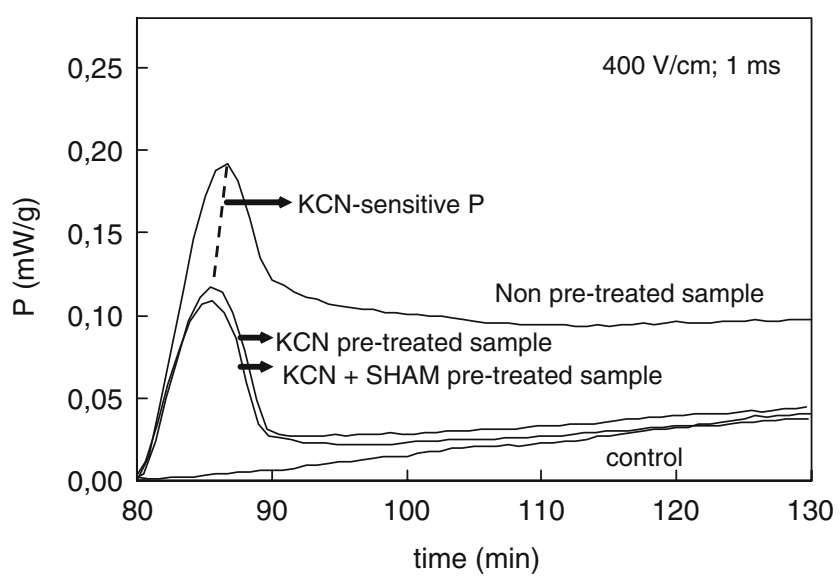

Fig. 4 Effect of metabolic inhibitors on thermal power. An example of the effect of pretreating the samples with $\mathrm{KCN}$ alone or in combination with SHAM is shown for the case of $400 \mathrm{~V} / \mathrm{cm}, 1 \mathrm{~ms}$. To facilitate comparison between the treatments, the thermal powers before the pulse have been subtracted and the peaks have been normalized to start at the origin. The different treatments are indicated next to the curves. The maximum thermal power that was shown to be $\mathrm{KCN}$ insensitive is depicted by the dashed line. Average curves of four replicates are shown

percentage of $P_{\max }$ was not inhibited by the $\mathrm{KCN}$, an exception is the total inhibition of $P_{\max }$ obtained by $\mathrm{KCN}$ at $200 \mathrm{~V} / \mathrm{cm}$ and $100 \mu$ s of field width. The percentage of KCN inhibition of $P_{\max }$ decreased with increasing field strength. The use of SHAM in combination with $\mathrm{KCN}$ represented less than $1 \%$ of the KCN-insensitive $P_{\max }$.

\section{Sample Impedance}

Figure 5a shows an example of the changes of tissue impedance with time after the application of the electric field $(200 \mathrm{~V} / \mathrm{cm} ; 1 \mathrm{~ms})$. It is interesting to note that at this field strength, the results showed a pronounced increase $(\sim 500 \Omega)$ of the impedance $30 \mathrm{~s}$ after the application of the pulse (indicated with an arrow in Figure 5a). After the first

Table 1 Effect of the application of PEF at different field widths and strengths on the $\mathrm{KCN}$-sensitive and $\mathrm{KCN}$-insensitive percentage of $P_{\max }$

\begin{tabular}{llcc}
\hline $\begin{array}{l}\text { Field strength } \\
\text { V/cm }\end{array}$ & $\begin{array}{l}P_{\max } \\
(\mathrm{mW} / \mathrm{g})\end{array}$ & $\begin{array}{l}\text { \% KCN- } \\
\text { sensitive } P_{\max }\end{array}$ & $\begin{array}{l}\text { \% KCN- } \\
\text { insensitive } P_{\max }\end{array}$ \\
\hline \multicolumn{2}{l}{ Field width $(1 \mathrm{~ms})$} & & \\
200 & $0.032 \pm 0.008$ & $51.8 \pm 8.4$ & $48.2 \pm 8.4$ \\
300 & $0.135 \pm 0.007$ & $56.0 \pm 6.5$ & $44.0 \pm 6.6$ \\
400 & $0.191 \pm 0.028$ & $43.4 \pm 3.4$ & $61.3 \pm 3.4$ \\
500 & $0.256 \pm 0.008$ & $32.8 \pm 7.3$ & $67.2 \pm 7.3$ \\
Field width $(100 \mu \mathrm{s})$ & & \\
200 & $0.023 \pm 0.008$ & $100.0 \pm 0.0$ & $0.0 \pm 0.0$ \\
300 & $0.032 \pm 0.004$ & $76.8 \pm 12.2$ & $23.2 \pm 12.2$ \\
400 & $0.035 \pm 0.025$ & $48.6 \pm 8.2$ & $51.4 \pm 8.2$ \\
500 & $0.040 \pm 0.008$ & $55.0 \pm 8.6$ & $45.0 \pm 8.6$ \\
\hline
\end{tabular}
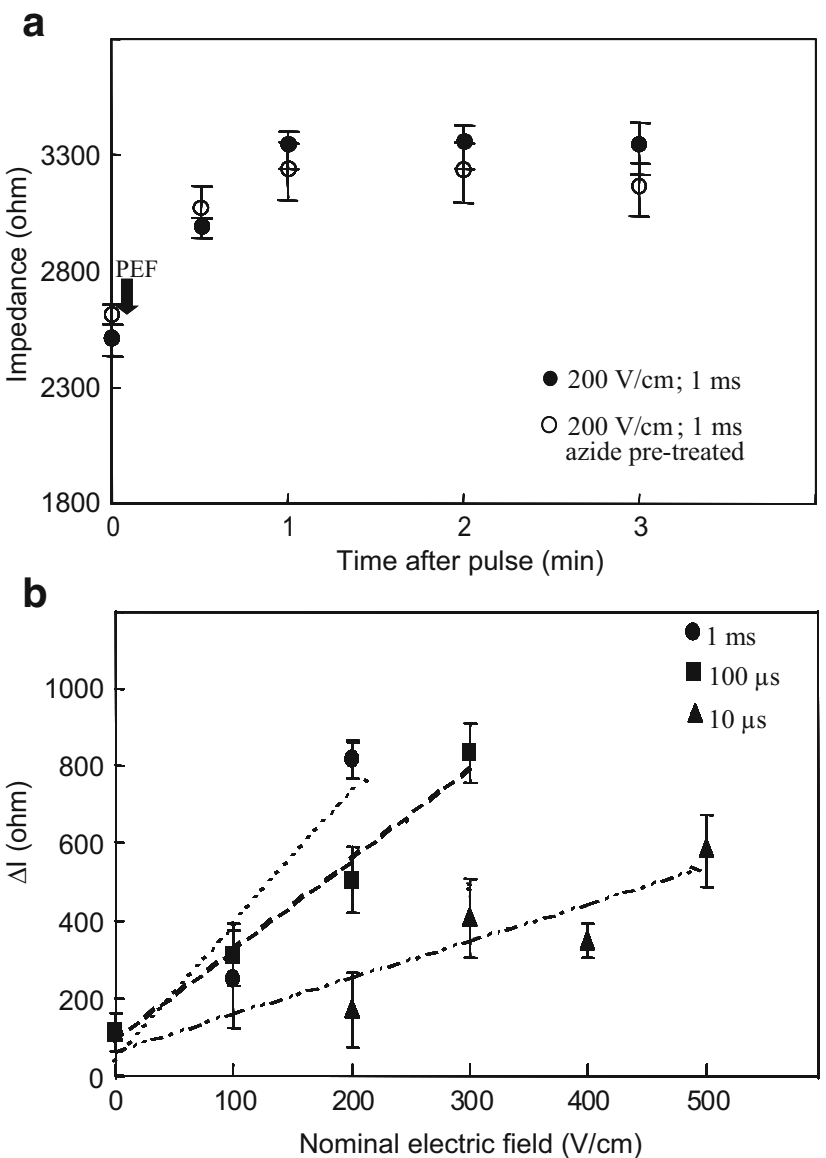

Fig. 5 Effect of electric field on sample impedance, as defined by Eq. 4. a An example of the variation of electrical impedance with postpulsation time is shown for the case when a pulse of $200 \mathrm{~V} / \mathrm{cm}, 1 \mathrm{~ms}$ was applied. The application of PEF is indicated with an arrow. The effect of pretreatment of the samples with sodium azide, as described in the "Materials and Methods" section, is shown. Each given value is the average of four replicates. Error bars are the standard deviation of the mean. b The difference between the impedance measured 1 min after the delivery of the pulse and the impedance measured before the delivery of the pulse $(\Delta I)$ is plotted against the applied electric field at different field widths

minute, it remained constant. This increase in the impedance values was mimicked by pretreating the potato tissue with $25 \mathrm{mM}$ solution of $\mathrm{H}_{2} \mathrm{O}_{2}$ for 5 min (not shown) but was not inhibited by pretreating the samples with sodium azide, a strong inhibitor of cell wall-associated peroxidases $^{23}$ (Figure 5a).

In Figure $5 b$, the absolute value of the difference between the impedance measured 1 min after the delivery of the pulse and the impedance measured before the delivery of the pulse $(\Delta I)$ was plotted against the applied electric field at different field widths. In the figure, the field strengths at which $\Delta I$ showed leakage of ions from the cells (negative values) after the delivery of the pulse are not reported. In the range of field strengths at which this leakage is not evident, $\Delta I$ increases linearly with increasing field strength. At field widths of $1 \mathrm{~ms}$ and $100 \mu \mathrm{s}, \Delta I$ 
reaches a maximum of $\sim 800 \Omega$ at 200 and $300 \mathrm{~V} / \mathrm{cm}$, respectively. At $10 \mu \mathrm{s}, \Delta I$ increases at all studied field strengths until a value of $\sim 500 \Omega$ at $500 \mathrm{~V} / \mathrm{cm}$.

\section{Discussion}

This study has explored metabolic responses of potato tissue upon the application of PEF. At pulse width of $1 \mathrm{~ms}$, the calorimetric measurements provide evidence that a fast metabolic response takes place upon the application of the electric pulse. With the application of PEF, opening of pores in the plasma membrane will result in the efflux and influx of polar molecules. After the pulse application, the resealing process is accompanied by oxidative stress with the consequent production of reactive oxygen species (ROS). ${ }^{1} \mathrm{H}_{2} \mathrm{O}_{2}$ is a major constituent of ROS production upon stress. ${ }^{24,25}$ Our calorimetric measurements support these facts. Results obtained with the $\mathrm{KCN}$ pretreatment (Table 1) suggest that oxygen consuming metabolic pathways such as respiration and production of $\mathrm{H}_{2} \mathrm{O}_{2}$ are part of the overall response. Depending on the pulsing conditions, the production of ROS has been reported to increase sharply on intact maize cells for 5 to $7 \mathrm{~min}$ after the application of the pulse until reaching a plateau. ${ }^{9}$ This result is consistent with the time scale in which the peak of the calorimetric curves reaches a maximum (Figures 2 and $3 a$ ). It has been reported for maize cells that the generation of ROS occurred many minutes after the resealing process was completed, as the presence of ROS could be detected even $1 \mathrm{~h}$ after pulsing. ${ }^{9}$ This observation is consistent with the fact that, after the peak of the calorimetric curves reached its maximum, the thermal power values did not decrease back to the initial level (Figures 2 and 3a), suggesting that PEF has induced a metabolic response lasting much longer than the expected time scale for the resealing process (seconds). In support of this idea, the peak of the curves corresponding to the KCN pretreated samples (see Figure 4 as an example) shows a decreasing curve to values closer to the origin, indicating that this long-lasting metabolic response may involve oxygen consuming pathways. However, the facts that a significant fraction of the total metabolic heat generated by the sample was not inhibited by $\mathrm{KCN}$ alone or in combination with SHAM and that the contribution of Joule heating to the overall response is very small, suggest that other factors, not necessarily oxygenconsuming, play a role. The last experimental observation provide strong evidence for that the cell membrane electropermeabilization and resealing involve much more than just structural changes in the lipid matrix; complex metabolic response that may involve several aspects such as energy release from the movement of ionic species, ATP hydrolysis to rebuild gradients of charges across cell membranes, and/ or other physiological events taking place during electropermeabilization as well as long after resealing could also be active. It has been demonstrated ${ }^{26}$ that a cell membrane that has been partially damaged has the ability to recover even if the damage has caused enhanced ion leakage. ATPase activity, which uses the chemical energy of ATP, is required for the recovery process, helping the cell to take up the leaked ions against the concentration gradient. This is a long-term physiological process that may take from several hours to days. ${ }^{26}$

When factors influencing the metabolic response to PEF were studied, results plotted in Figure $3 \mathrm{~b}$ showed that this response is strongly influenced by the intensity and width of the pulse. It is interesting to note that the fact that the observed electroporation of the tissue (Figure 1) reaches similar levels when widths of $1 \mathrm{~ms}$ and $100 \mu \mathrm{s}$ were applied shows that the metabolic response is independent of the total permeabilization achieved by the pulse. This observation is more obvious when the pulse width of $10 \mu \mathrm{s}$ was applied, where a drastic decrease of the resistance of the tissue was not accompanied by a measurable metabolic response. These results are supported by the lack of correlation between $P_{\max }$ and the resistance of the tissue during the delivery of the pulse, in the low range of resistance values, illustrated in Figure 3c. Our results strongly suggest that the size and the persistence of the created pores are key factors affecting the response. In studies on lipid bilayers, it was shown that the size and the distribution of the pores will depend on the pulsing conditions. Certain PEF conditions may create many small, transient pores (around 1.5-nm radius), that would relax and reseal in a time scale of $n s,{ }^{27,28}$ with stronger PEF conditions, the distribution of pore sizes would include larger pores (around 50-nm radius) which tend to reseal more slowly ( $>1 \mathrm{~s}$ in some cases) or not at all. ${ }^{28}$ It is possible that in both cases, the total decrease of resistance is similar. However, the metabolic work that the cell needs to do when dealing with the formation of small or large pores is different and may depend on the extent of polar compounds migrating upon electroporation as well as the amount of energy required for resealing and further recovery.

When electrical impedance was used to evaluate the progress of cell membrane permeabilization after stress application, the results plotted in Figure 5, showing that the impedance of the samples increases drastically after pulsation, were unexpected. They first suggested that PEF had loosened the contact between the electrodes and the sample, with a consequent increase on the impedance values. We checked this possibility by inserting wet (in potato juice) filter paper in between the sample and the electrodes before PEF application. The result was that the impedance increase persisted for all tested conditions. A 
decrease of the extracellular volume has been reported to result on a fast impedance increase. ${ }^{29}$ In a previous report, Gómez Galindo et al. ${ }^{30}$ showed that PEF decreased cell wall permeability to the fluorescent dye FM1-43, suggesting a decrease on cell wall porosity. This was a fast response already detected $30 \mathrm{~s}$ after the delivery of the electric field. The authors showed that this response was mimicked by exogenous $\mathrm{H}_{2} \mathrm{O}_{2}$ and blocked by sodium azide, an inhibitor of the production of $\mathrm{H}_{2} \mathrm{O}_{2}$ by peroxidases. Our results, showing that the fast impedance increase was mimicked by exogenous $\mathrm{H}_{2} \mathrm{O}_{2}$ suggests that changes on cell wall structure might be linked with the impedance increase. However, the fact that sodium azide did not block the impedance increase was not encouraging and we did not elaborate further into this hypothesis. An interesting possibility is that, at conditions at which cell electroporation does not induce cell leakage, the concentration of charged molecules, small enough to contribute to impedance measurements, decreases within seconds after the application of the pulse. It has been demonstrated that application of PEF to culture cells of tomato at voltages compatible with cell survival, directly opens voltage-gated calcium permeable channels elevating cytosolic free $\mathrm{Ca}^{2+} .31$ The $\mathrm{Ca}^{2+}$ channel activation is steeply voltage-dependent. ${ }^{32}$ The huge $\mathrm{Ca}^{2+}$ concentration difference between $\mathrm{Ca}^{2+}$ stores in cell walls (in concentration in the range of $\mathrm{mM}$ ) and cytosol $(<1 \mu \mathrm{M})^{33}$ would allow an influx of $\mathrm{Ca}^{2+}$ through the opened channels that might substantially decrease the total concentration of ionic species in the apoplast. Sustained or transient elevations of cytosolic $\mathrm{Ca}^{2+}$ concentration evoke downstream stimulus-specific responses, ${ }^{32}$ including the signal transduction leading to the activation of mitogen-activated protein (MAP) kinases which is a common stress reaction of plant cells in defense-related signal transduction pathways. ${ }^{31}$ Eventually, $\mathrm{Ca}^{2+}$ may be pumped out of the cell, restoring equilibrium. However, in this investigation, we have only focused our attention in the first minutes after the pulse as in longer time scales our samples may be affected by other stress conditions such as the wound healing process and the decrease of the concentration of oxygen in the closed ampoules used in our experimental setup.

\section{Concluding Remarks}

This study, exploring metabolic responses of potato tissue upon the application of pulsed electric fields, has resulted in striking results as well as in interesting questions. The following remarks underline important findings:

(1) The metabolic response of potato tissue to the application of PEF involves oxygen consuming path- ways as well as other unidentified events that are shown to be insensitive to metabolic inhibitors such as $\mathrm{KCN}$, SHAM, and sodium azide.

(2) The metabolic response is strongly dependent on pulsing conditions and is independent on the total permeabilization achieved by the pulse.

In this study, we provide evidence that calorimetry is a simple and powerful method for exploring conditions for metabolic stimulation, providing information on metabolic responses that can not be obtained from electrical measurements.

Our exploration study has set the basis for further investigations on:

(1) Effect of transient loss of internal compartmentalization on cellular composition, structure, and metabolic activity.

(2) Defense-related consequences of PEF-induced stress.

Investigations of the genetic control of metabolism through techniques such as transcriptomics and metabolic profiling, will contribute to expand our knowledge in the field.

Acknowledgements The authors would like to thank Allan G. Rasmusson from the Department of Cell and Organism Biology and Marianne Sommarin from the Department of Plant Biochemistry, Lund University, Sweden for the enlightening discussions. This study was supported by grants from the Portuguese Foundation of Science and Technology and Sparbanksstiftelsen Färs \& Frosta, Sweden.

\section{References}

1. J. Teissié, M. Golzio, M.P. Rols, Biochim. Biophys. Acta (G) 1724, 270 (2005)

2. M.M. Góngora-Nieto, P.D. Pedrow, B.G. Swanson, G.B. BarbosaCanovas, J. Food Eng. 57, 209 (2003)

3. S. Toepfl, V. Heinz, D. Knorr, Chem. Eng. Process. 46, 537 (2007)

4. M. Fincan, F. DeVito, P. Dejmek, J. Food Eng. 64, 381 (2004)

5. Y. Chalermchat, P. Dejmek, J. Food Eng. 71, 164 (2005)

6. B.I.O. Ade-Omowaye, N.K. Rastogi, A. Angersbach, D. Knorr, J. Food Eng. 60, 89 (2003)

7. N.I. Lebovka, N.V. Shynkaryk, E. Vorobiev, J. Food Eng. 78, 606 (2007)

8. B. Gabriel, J. Teissié, Eur. J. Biochem. 223, 25 (1994)

9. N. Sabri, B. Pelissier, J. Teissié, Eur. J. Biochem. 238, 737 (1996)

10. H. Ye, L.L. Huang, S.D. Chen, J.J. Zhong, Biotechnol. Bioeng. 88, 788 (2004)

11. M. Guderjan, P. Elez-Martinez, D. Knorr, Innov. Food Sci. Emerg. Technol. 8, 55 (2007)

12. M. Guderjan, S. Topfl, A. Angersbach, D. Knorr, J. Food Eng. 67, $281(2005)$

13. F. Gómez Galindo, I. Sjöholm, A.G. Rasmusson, S. Widell, K. Kaack, Crit. Rev. Food Sci. Nutr. 47, 729 (2007)

14. C.J. Atkinson, R. Nestby, Y.Y. Ford, P.A.A. Dodds, Biofactors 23, 229 (2005)

15. M. Schreiner, S. Huyskens-Keil, Crit. Rev. Plant Sci. 25, 267 (2006) 
16. R.S. Criddle, R.W. Breindenbach, L.D. Hansen, Thermochim. Acta 193, 67 (1991)

17. K. Kinosita, T.Y. Tsong, Biochim. Biophys. Acta 471, 227 (1977)

18. Y. Chalermchat. Effects of Pulsed Electric Fields on Plant Tissue, $\mathrm{PhD}$ Thesis. Lund University, Sweden (2005)

19. P. Rocculi, F. Gómez Galindo, F. Mendoza et al., Post Biol Tech. 43, 151 (2007)

20. L. Wadsö, Cement Int. 5, 94 (2005)

21. I. Wadsö, R.N. Goldberg, Pure Appl. Chem. 73, 1625 (2001)

22. L. Wadsö, F. Gomez Galindo, I. Sjöholm, P. Rocculi, Thermochim. Acta 422, 89 (2004)

23. F. Razem, M.A. Bernards, J. Exp. Bot. 54, 935 (2003)

24. D.J. Bradley, P. Kjelbom, C.J. Lamb, Cell 70, 21 (1992)

25. P. Wojtaszek, Biochem 322, 681 (1997)
26. R. Arora, J.P. Palta, Plant Physiol. 95, 846 (1991)

27. R.P. Joshi, Q. Hu, K.H. Schoenbach, IEEE Trans. Plasma Sci. 30 , $1536(2002)$

28. Z. Ji, S. Kennedy, J.H. Booske, S.C. Hagness, IEEE Trans. Plasma Sci. 34, 1416 (2006)

29. L.F. Ruis-Heutinck, B. Savenije, F. Postema, A. Van Voorst, E. Lambooij, J. Korf, Poultry Sci. 77, 1422 (1998)

30. F. Gómez Galindo, P.T. Vernier, P. Dejmek, A. Vicente, M.A. Gundersen, Bioelectromagnetics, 29, 296 (2008)

31. V.L. Link, M.G. Hofmann, A.K. Sinha, R. Ehness, M. Strnad, T. Roitsch, Plant Physiol. 128, 271 (2002)

32. E. Peiter, F.J.M. Maathuis, L.N. Mills et al., Nature 434, 404 (2005)

33. I.I. Pottosin, G. Schönknecht, J. Exp. Bot. 58, 1559 (2007) 